\title{
Características físico-químicas de bebidas de café tipo expresso preparadas a partir de blends de café arábica e conilon ${ }^{1}$
}

\author{
Tarcísio Lima Filho², Suzana Maria Della Lucia ${ }^{3 *}$, Sérgio Henriques Saraiva ${ }^{3}$, Rondinelli Moulin Lima ${ }^{4}$ \\ http://dx.doi.org/10.1590/0034-737X201562040001
}

\begin{abstract}
RESUMO
Nos últimos anos tem sido crescente a procura por bebidas de café diferenciadas, como o tipo expresso. Nessa bebida, é essencial um alto teor de extrato aquoso para garantir um bom corpo, o que pode ser obtido utilizando-se o café conilon. O Estado do Espírito Santo é o maior produtor nacional de café conilon. Ainda que existam vários estudos sobre a composição físico-química do café brasileiro, pouco se sabe sobre características físico-químicas das bebidas de café expresso obtidas com blends entre o café arábica e o conilon capixaba. Neste trabalho teve-se como objetivo realizar a caracterização físico-química da bebida de café expresso formulada a partir de blends de café arábica e conilon produzido no Espírito Santo (nas proporções de arábica e conilon de 100:0; 80:20; 60:40; 40:20; e 0:100, respectivamente), com diferentes tipos de processamento (natural e descascado). Foram realizadas análises de umidade, $\mathrm{pH}$, acidez titulável total e extrato aquoso. Constatou-se que a utilização de conilon no blend com arábica, nas duas formas de processamento, acarreta em bebidas com maior valor de $\mathrm{pH}$, menor acidez e maior teor de extrato aquoso. Um maior teor de extrato aquoso é interessante para o preparo de café tipo expresso. Sendo assim, os resultados demonstram a viabilidade da utilização do café conilon em blends com arábica no preparo do café tipo expresso, quando se desejam bebidas com maior teor de extrato aquoso.
\end{abstract}

Palavras-chave: café capixaba, pH, acidez titulável total, extrato aquoso.

\section{ABSTRACT}

\section{Physico-chemical characterization of espresso coffee beverage prepared from blends of arabica and conilon coffees}

In recent years, there has been a growing interest for exquisite beverages such as espresso coffee. Espresso coffee requires a high content of the aqueous extract to ensure a good body of the beverage, which can be obtained using coffee conilon. Espírito Santo State is the largest producer of conilon coffee in Brazil. Although there are several studies on the physico-chemical composition of Brazilian coffee, there is a lack of information about the use of conilon from Espírito Santo in the formulation of blends with Arabica coffee, as well as the physico-chemical characteristics of espresso coffee beverage obtained with these blends. The objective of this study was to carry out the physico-chemical characterization of espresso coffee beverage made from blends of arabica and conilon coffees (in arabica and conilon proportions of 100:0; 80:20;60:40; 40:20 and 0:100, respectively) with different types of processing (dry process and semi dry process) produced in Espírito Santo. The variables moisture, $\mathrm{pH}$, titratable acidity and aqueous extract of the samples were analyzed. It was found that the use of conilon in blends

\footnotetext{
Submetido em 17/02/2014 e aprovado em 08/07/2015.

'Este trabalho é parte do projeto de iniciação científica do primeiro autor, financiado pela Universidade Federal do Espírito Santo.

${ }^{2}$ Universidade Federal do Espírito Santo, Departamento de Engenharia de Alimentos, Alegre, Espírito Santo, Brasil. tarcisiolimaf@yahoo.com.br

${ }^{3}$ Universidade Federal do Espírito Santo, Departamento de Engenharia de Alimentos, Alegre, Espírito Santo, Brasil. smdlucia@yahoo.com.br; sergiohsaraiva@gmail.com

${ }^{4}$ Universidade Federal do Espírito Santo, Departamento de Engenharia de Alimentos, Alegre, Espírito Santo, Brasil. rondinelli_ml@hotmail.com

*Autora para correspondência: smdlucia@yahoo.com.br
} 
with Arabica, in the two forms of processing, results in beverages with higher levels of $\mathrm{pH}$, lower acidity and higher percentage of aqueous extract. A higher percentage of aqueous extract is interesting for the preparation of espresso coffee. The results demonstrate the feasibility of using conilon coffee in blends with Arabica coffee in brewing espresso coffee, when a higher aqueous extract beverage is desired.

Key words: Espírito Santo coffee, $\mathrm{pH}$, titratable acidity, aqueous extract.

\section{INTRODUÇÃO}

O consumo de café expresso tem aumentado nos últimos anos devido à maior procura dos consumidores por produtos diferenciados e aos maiores investimentos em melhoria da qualidade do café (Mendes, 2005; Navarini \& Rivetti, 2010). O preparo deste tipo de café exige grãos de alta qualidade, com aroma e sabores intensos e que possibilitem a obtenção de bebidas com ótimo corpo (Pinto et al., 2002). Algumas das alternativas para as indústrias obterem tal qualidade e garantirem um produto final superior para o consumidor são a utilização de blends (misturas de cafés) e o emprego de cafés submetidos a formas de processamento que maximizem as características desejadas.

O processamento do café pode ser realizado por via seca (gera o café natural), via úmida com fermentação (café despolpado) ou por via úmida sem fermentação (café descascado). O processamento por via úmida tem a vantagem, sobre o processamento por via seca, de diminuir a ocorrência de fermentações indesejáveis do café, o que ajudaria a garantir um produto final de melhor qualidade (Pimenta, 2003).

Alguns dos blends utilizados pelas indústrias podem ser formulados com a mistura de cafés arábica e conilon, em diferentes proporções. O café arábica é mais frutado e ácido, enquanto o café conilon é mais amargo e garante bebidas mais encorpadas (Fonseca et al., 2007). Embora o arábica seja a espécie mais comumente empregada na elaboração do café tipo expresso, estudos anteriores com blends contendo proporções de até $60 \%$ de conilon natural e descascado sugeriram que este último café pode ser utilizado, desde que de boa qualidade, em blends com café arábica sem que a qualidade final da bebida desejada pelo consumidor seja comprometida (Mendes, 2005; Lima Filho et al., 2011).

Estudos demonstram que a complexa composição físico-química do café define a qualidade final da bebida, sendo responsável por suas características sensoriais (Pimenta, 2003). A acidez dos grãos de café tem sido relacionada com a qualidade do produto. Sua intensidade está relacionada a vários fatores como os níveis de fermentação ocorrida nos grãos, condições climáticas durante a colheita e secagem, estádios de maturação, local de origem e forma de preparo (Pimenta, 2003; Siqueira \& Abreu, 2006).

$\mathrm{O}$ pH é um indicador de eventuais mudanças nos frutos de café, como o processo indesejável de fermentação que ocorre na pré e pós-colheita, originando defeitos do produto. De acordo com Siqueira \& Abreu (2006), o pH ideal deve estar entre 4,95 a 5,20, tornando as características sensoriais do café mais aceitáveis pelo consumidor, sem excesso de amargor ou acidez.

Geralmente é desejável no café um maior teor de extrato aquoso, tanto pelo ponto de vista do rendimento industrial, como pela sua contribuição para assegurar o corpo da bebida, indispensável em cafés tipo expresso (Pinto et al., 2002).

Contudo, ainda que inúmeros estudos tenham investigado a influência da forma de processamento ou de blends de espécies de café nas características sensoriais e físico-químicas da bebida (Albanese et al. , 2009; Santos et al., 2009; Kleinwächter \& Selmar, 2010; Duarte et al., 2010, Santos, 2010; Saraiva, et al., 2010; Lima Filho et $a l .$, 2011), são poucos os estudos que investigam as características físico-químicas de bebidas provenientes da mistura de café conilon, produzido no Estado do Espírito Santo e submetido a diferentes formas de processamento, com o café arábica (Coffea arabica L.) para o preparo da bebida de café tipo expresso. Estudos desse tipo são de fundamental importância, uma vez que o Espírito Santo é o maior produtor de café conilon do Brasil, com aproximadamente $77 \%$ da produção nacional (CONAB, 2013), e que a composição físico-química é determinada, dentre outros fatores, por sua região de origem, genética, clima, altitude, sistema de cultivo e formas de processamento (Pimenta, 2003).

Em estudo anterior avaliaram-se as características sensoriais e aceitação sensorial de café expresso produzido com blends de café arábica e conilon em proporções de até $60 \%$ de conilon na mistura final. Nesse estudo foram verificadas maior intensidade de aroma caramelizado nas bebidas de café $100 \%$ arábica descascado e maior intensidade de gosto amargo nas bebidas à medida que se aumentou o teor de café conilon no blend. Apesar dessas diferenças nas características sensoriais, não houve diferença significativa na aceitação das misturas estudadas (Lima Filho et al., 2011). 
Dando continuidade ao trabalho de Lima Filho et al., 2011 o objetivo do presente trabalho foi realizar a caracterização físico-química de bebidas de café expresso obtidas a partir de blends entre café arábica e conilon produzidos no estado do Espírito Santo e submetidos a duas formas de processamento.

\section{MATERIAL E MÉTODOS}

\section{Material}

Os grãos de café utilizados neste estudo foram da espécie Coffea arabica L. cultivar Catuaí da safra 2009/ 2010, provenientes da Fazenda Experimental de Venda Nova do Imigrante do Incaper - Instituto Capixaba de Pesquisa, Assistência Técnica e Extensão Rural, e da espécie Coffea canephora Pierre cultivar Robusta Tropical da safra 2009/2010, provenientes da Fazenda Experimental Bananal do Norte do Incaper, localizada em Pacotuba - Cachoeiro de Itapemirim - ES. Nos respectivos locais onde foram colhidos, os grãos também passaram por etapas de processamento, secagem e beneficiamento.

\section{Preparo das amostras}

Para cada espécie de café a colheita foi realizada em peneira e de forma seletiva, colhendo-se apenas os grãos cereja. O café foi colhido, lavado e dividido em dois lotes. Cada lote de café foi submetido a uma forma de processamento. Um lote foi processado por via seca, processamento em que o café foi levado diretamente para o terreiro suspenso para etapa de secagem, constituindo a parcela de café natural. No outro lote, submetido ao processamento via úmida sem fermentação, retirou-se, mecanicamente, apenas a casca dos grãos de café, dando origem ao café descascado. Após a etapa de processamento os lotes passaram pela etapa de secagem em terreiro de tela suspensa. Em seguida, foi realizado o beneficiamento do café, etapa em que foram retiradas impurezas dos lotes e retirada a casca e pergaminho do café natural, dando origem ao café cru (Lima Filho et al., 2013).

Os processos de torrefação e moagem do café foram realizados no Laboratório de Operações Unitárias e as análises físico-químicas no Laboratório de Química de Alimentos do Departamento de Engenharia de Alimentos, no Centro de Ciências Agrárias da Universidade Federal do Espírito Santo (CCA-UFES), na cidade de Alegre - ES.

Para obtenção do grão torrado expresso, o café cru foi torrado em torrador/moedor de prova a gás, marca Pinhalense, apresentando coloração referente ao ponto \#55 do disco de cores Agtron-SCAA, caracterizando, assim, torra média (ABIC, 2012).
Para cada forma de processamento (café natural e café descascado), após a torra, 200 g de café arábica e de café conilon foram separados, representando as amostras $100 \%$ arábica e $100 \%$ conilon. Além das amostras $100 \%$ arábica e $100 \%$ conilon foram preparados os seguintes blends de café arábica e conilon, respectivamente: 80:20; 60:40 e 40:60. Posteriormente, as amostras foram moídas (no mesmo torrador/moedor utilizado na torra) em granulometria específica para café expresso. As bebidas de café foram preparadas em máquina para café expresso marca Electrolux Chef Crema a partir das formulações, utilizando $9 \mathrm{~g}$ de pó de café para preparar $50 \mathrm{~mL}$ de bebida, conforme recomendações para preparo de café expresso e informações contidas no manual da máquina.

\section{Análises Físico-Químicas}

Foram realizadas análises físico-químicas de umidade nos grãos de café crus e torrados e de $\mathrm{pH}$, acidez titulável total e extrato aquoso (variáveis dependentes ou variáveis resposta) nas bebidas de café expresso obtidas com os blends de café das duas formas de processamento.

\section{Umidade}

A umidade dos grãos crus foi determinada por analisador de umidade e impurezas modelo G650, marca Gehaka Agri.

A determinação da umidade dos grãos torrados foi realizada pelo método de secagem direta em estufa (IAL, 2008). Uma alíquota de $10 \mathrm{~g}$ de café moído foi submetida à secagem em estufa a $105^{\circ} \mathrm{C}$ até peso constante. $\mathrm{O}$ resultado foi expresso em porcentagem de umidade $(\mathrm{m} /$ m) em base úmida.

\section{$p H$}

$\mathrm{O}$ pH da bebida de café expresso foi medido por potenciômetro, à temperatura ambiente, utilizando pHmetro modelo mPA-210, marca Tecnopon (IAL, 2008).

\section{Acidez, titulável total (ATT)}

Como a coloração do café impossibilita a visualização do ponto de viragem, quando utilizada solução indicadora, a análise foi realizada com auxílio de pHmetro. A medição foi realizada por titulação com $\mathrm{NaOH} 0,1 \mathrm{~N}$ até $\mathrm{pH}$ 8,2 , sob temperatura ambiente. Os resultados foram expressos em mL de $\mathrm{NaOH}$ em 100 g de café (IAL, 2008).

\section{Extrato aquoso (EA)}

Uma alíquota de $50 \mathrm{~mL}$ de bebida de café expresso passou por etapa de filtragem por ação da gravidade utilizando o conjunto papel de filtro-funil. Posteriormente, o filtrado foi seco em banho-maria a $70{ }^{\circ} \mathrm{C}$ (IAL, 
2008). O resultado foi expresso em porcentagem de extrato aquoso $(\mathrm{m} / \mathrm{m})$.

\section{Delineamento experimental e análise estatística}

$\mathrm{Na}$ Tabela 1 estão apresentadas as descrições dos fatores e níveis que compuseram os tratamentos em estudo. $\mathrm{O}$ número de tratamentos correspondeu às combinações entre os fatores e seus níveis, de modo que as análises físico-químicas foram realizadas em 10 tratamentos.

$\mathrm{O}$ experimento foi realizado em um delineamento inteiramente casualizado, sob arranjo fatorial com 10 tratamentos, com um fator qualitativo (tipo de processamento, em dois níveis) e um quantitativo (proporções de conilon e arábica nos blends, em 5 níveis), em três repetições. Realizou-se uma análise de variância univariada e, para verificar o efeito das proporções de conilon no blend sobre as variáveis resposta, foi empregada a análise de regressão linear (Ribeiro Júnior, 2001). Este procedimento foi realizado para cada variável físico-química analisada.

Os resultados alcançados foram comparados com dados da literatura, de modo a permitir uma maior compreensão da variação da composição físico-química do café devido à variação da concentração de conilon e arábica nos blends.

\section{RESULTADOS E DISCUSSÃO}

Os valores de umidade das amostras de café estão apresentados na Tabela 2. A umidade dos grãos crus está de acordo com a Instrução Normativa ${ }^{\circ} 8$, de 11 de junho de 2003, estabelecida pelo Ministério da Agricultura, Pecuária e Abastecimento (Brasil, 2003), em que é definido que o teor de umidade do café beneficiado grão cru não pode exceder o limite máximo de tolerância de 12,5\%. De acordo com a Instrução Normativa $n^{\circ} 16$, de 24 de maio de 2010, estabelecida pelo Ministério da Agricultura, Pecuária e Abastecimento (Brasil, 2010), o café torrado deve conter um teor de umidade de, no máximo, $5 \%$. As amostras de café torrado expresso analisadas estão dentro do padrão estipulado pela legislação.

A ANOVA dos dados do café expresso demonstraram não haver interação significativa entre os fatores processamento e blend para todas as variáveis resposta em estudo, ou seja, os fatores em estudo atuam de forma independente (Tabela 3).

Conforme demonstrado na Tabela 3, as médias de $\mathrm{pH}$ da bebida de café expresso proveniente de grãos de café natural $(5,25)$ e proveniente de grãos de café descascado $(5,31)$ foram estatisticamente iguais $(p>0,05)$. As médias de acidez titulável total (ATT) da bebida de café expresso natural $(190,133 \mathrm{~mL}$ de $\mathrm{NaOH} 0,1 \mathrm{~N} / 100 \mathrm{~g}$ de amostra) e da bebida de café expresso descascado (187,733 mL de NaOH 0,1N/100 g de amostra) também foram estatisticamente iguais $(\mathrm{p}>0,05)$.

Dentre as formas de processamento, o café natural é o que está mais susceptível à ocorrência de fermentações indesejadas. A acidez e o pH são indicadores de eventuais mudanças devido a essas fermentações. No presente trabalho, as etapas pós-colheita do café natural e do café descascado foram realizadas de maneira a garantir um produto final dentro dos padrões de qualidade, sem a ocorrência de fermentações indesejadas, o que pode explicar os resultados encontrados, não havendo diferenças nas médias de $\mathrm{pH}$ e acidez titulável total devido à forma de processamento.

Tabela 1: Fatores dos tratamentos e respectivos níveis

\begin{tabular}{ll}
\hline Fator & Níveis / descrição \\
\hline Tipo de processamento do café & 1 - Natural (via seca) \\
& 2 - Descascado (via úmida sem fermentação) \\
\hline Proporção de café arábica e conilon, respectivamente, nos blends & $1-100: 0$ \\
& $2-80: 20$ \\
& $3-60: 40$ \\
& $4-40: 60$ \\
$5-0: 100$
\end{tabular}

Tabela 2: Umidade de grãos de cafés crus e torrados utilizados nos blends destinados ao preparo de café expresso

\begin{tabular}{|c|c|c|}
\hline \multirow{2}{*}{ Amostras } & \multicolumn{2}{|c|}{ Umidade $(\% \mathrm{~m} / \mathrm{m}) *$} \\
\hline & Café cru & Café torrado (expresso) \\
\hline \multirow{2}{*}{ Natural } & Arábica $10,91 \pm 0,23$ & $2,16 \pm 0,35$ \\
\hline & Conilon $11,11 \pm 0,15$ & $1,08 \pm 0,03$ \\
\hline \multirow{2}{*}{ Descascado } & Arábica 11,11 $\pm 0,09$ & $2,06 \pm 1,33$ \\
\hline & Conilon $10,49 \pm 0,14$ & $0,88 \pm 0,77$ \\
\hline
\end{tabular}

* Média \pm desvio padrão de três valores. (Teores de umidade em base úmida) 
As médias de extrato aquoso (EA) do café expresso natural $(15,34 \% \mathrm{~m} / \mathrm{m})$ e café expresso descascado $(13,79 \% \mathrm{~m} / \mathrm{m})$ foram significativamente diferentes. $\mathrm{Na}$ literatura, não foram encontrados estudos que determinassem o teor de extrato aquoso da bebida de café tipo expresso para possibilitar uma comparação com os resultados encontrados no presente estudo.

Para o fator blend, foi verificado efeito significativo $(\mathrm{p}<0,05)$ em todas as variáveis respostas em estudo (Tabela 3), ou seja, as médias de $\mathrm{pH}$, acidez titulável total e extrato aquoso dos blends de café expresso foram significativamente diferentes. Para estudar o comportamento da variação destas médias de acordo com o blend foi realizada regressão linear. Como o fator processamento não apresentou efeito significativo nas variáveis $\mathrm{pH}$ e acidez, foi ajustado apenas um modelo matemático com a média dos valores de $\mathrm{pH}$ e acidez de cada blend da bebida de café expresso proveniente de grãos de café natural e de café descascado (Figura 1, Figura 2). Para a variável extrato aquoso, foram ajustados dois modelos matemáticos, um para cada forma de processamento (natural ou descascado) (Figura 3).
Para todas as variáveis resposta, o modelo que melhor se adequou foi o linear, uma vez que foi constatado efeito significativo $(\mathrm{p}<0,05)$ na análise de variância e elevado coeficiente de determinação $\left(\mathrm{r}^{2}\right)$.

Na Figura 1 observa-se que houve aumento no valor de $\mathrm{pH}$ à medida que se aumentou a concentração de conilon no blend. Segundo Mendes (2005) e Fonseca et al. (2007), o café arábica apresenta maior acidez que o café conilon, o que pode explicar o comportamento do $\mathrm{pH}$ das misturas. Os valores de $\mathrm{pH}$ encontrados estão condizentes com os valores encontrados por Pinto et al. (2002) para café expresso.

Na Figura 2 pôde-se verificar uma diminuição da acidez titulável total à medida que se aumentou a concentração de conilon no blend, resultado explicado pelo fato de o café conilon ser menos ácido que o café arábica, como comentado anteriormente. Este resultado foi condizente com o encontrado na análise de $\mathrm{pH}$ para os mesmos blends de café expresso, uma vez que o aumento da concentração de conilon no blend ocasionou um aumento no $\mathrm{pH}$.

Na Figura 3 são apresentados os resultados de extrato aquoso das bebidas de café expresso provenien-

Tabela 3: Resumo da significância obtida na análise da variância para pH, acidez titulável total e extrato aquoso de café expresso, em resposta a blends conilon $\mathrm{x}$ arábica e formas de processamento pós-colheita

\begin{tabular}{llc}
\hline Variáveis resposta & Fatores & Significância do teste \\
\hline \multirow{2}{*}{$\mathrm{pH}$} & Blend & $*$ \\
& Processamento & $\mathrm{ns}$ \\
& Blend*processamento & $\mathrm{ns}$ \\
Acidez & Blend & $*$ \\
& Processamento & $\mathrm{ns}$ \\
& Blend*processamento & $\mathrm{ns}$ \\
Extrato aquoso & Blend & $*$ \\
& Processamento & $*$ \\
\hline
\end{tabular}

ns = não significativo; $*$ = significativo

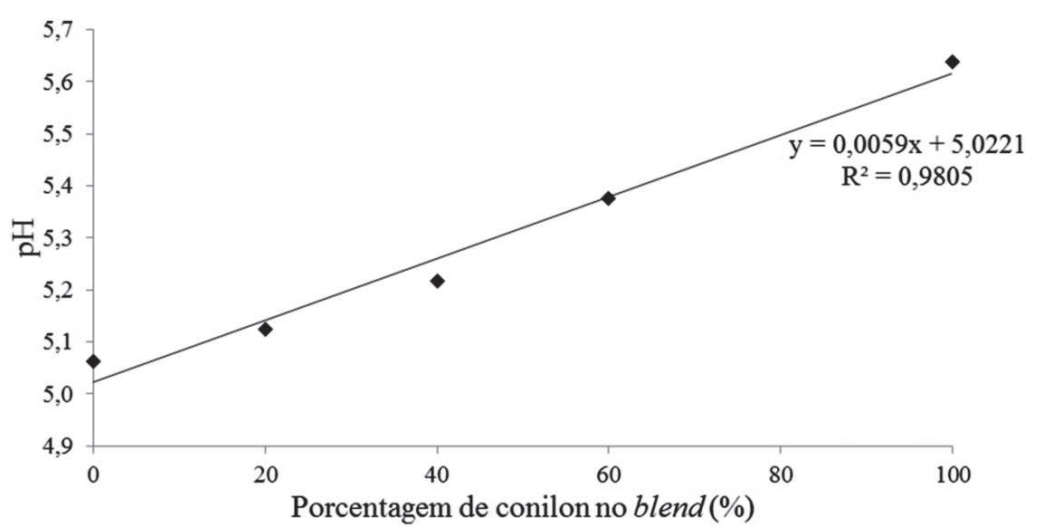

Figura 1: Valores de pH da bebida de café expresso em função da adição de proporções crescentes de café conilon no blend com arábica. 
tes de café natural e das bebidas de café expresso provenientes de café descascado. Verificaram-se, para as duas formas de processamento, um aumento no EA com o aumento da concentração de conilon no blend. Estes resultados são compatíveis aos encontrados na literatura, uma vez que o café conilon gera bebidas mais encorpadas que o café arábica, e existe uma relação entre o teor de extrato aquoso e o corpo da bebida (Fonseca et al., 2007). Geralmente, é desejável no café expresso um maior teor de extrato aquoso, tanto pelo ponto de vista do rendimento industrial, como pela sua contribuição para assegurar o corpo da bebida, indispensável em cafés tipo expresso (Pinto et al., 2002).

De acordo com a portaria $\mathrm{n}^{\circ} 377$, de 26 de abril de 1999, estabelecida pela ANVISA, o café torrado deve conter um teor mínimo de extrato aquoso de $25 \%$ (g/ 100g) (Brasil, 1999). Os teores de extrato aquoso de todos os blends em estudo encontraram-se abaixo do determinado pela legislação. Esta diferença era esperada e pode ser justificada devido à forma de extração do café. A extração realizada pela máquina de café expresso, no preparo da bebida, tem como objetivo extrair apenas compostos desejáveis para uma boa qualidade sensorial da bebida de café tipo expresso, diferentemente da extração realizada na análise de café torrado, cujo objetivo é extrair o máximo de compostos solúveis do pó de café, por meio de extrator de Soxhlet, por exemplo (Clifford \& Wight, 1979).

Os resultados evidenciam aumento no $\mathrm{pH}$, queda da acidez titulável total e aumento do teor de extrato aquoso da bebida de café tipo expresso em função do aumento da proporção de café conilon no blend com arábica. Cabe salientar que mesmo com as alterações físico-químicas encontradas no presente estudo, estudos encontrados na literatura têm demonstrado que a adição de 50- 60\% de café conilon em blends com café arábica não compromete a aceitação sensorial de bebida de café (Mendes, 2005; Lima Filho et al., 2011; CETCAF, 2012).

Mendes (2005) avaliou a aceitação sensorial de bebidas de café tipo expresso formuladas a partir de blends de café arábica, proveniente de São Paulo, com café conilon capixaba descascado (nas proporções de $100 \%$ arábica e $10 \%, 20 \%, 30 \%, 40 \%$ e $50 \%$ de conilon no blend). Não houve diferença significativa $(\mathrm{p}>0,05)$ na aceitação das bebidas de café expresso, independentemente da concentração de conilon no blend.

Lima Filho et al. (2011) realizaram a caracterização sensorial e avaliaram a aceitabilidade de bebidas de café tipo expresso preparadas a partir dos mesmos blends do presente estudo, à exceção da amostra $100 \%$ conilon. Por meio da Análise Descritiva Quantitativa verificou-

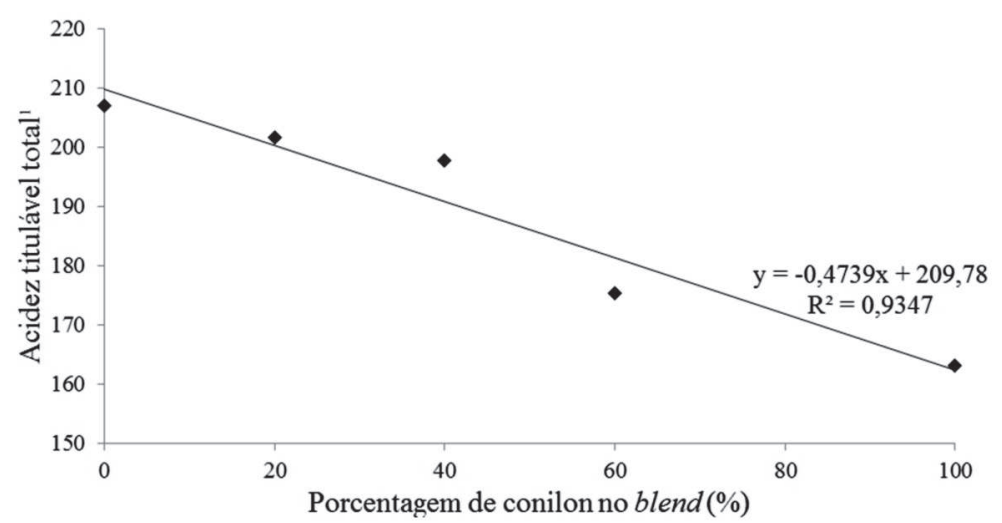

Figura 2: Valores de ATT da bebida de café expresso em função da adição de níveis crescentes de conilon no blend com arábica. ${ }^{1}$ Acidez titulável total expressa em acidez em solução molar por $100 \mathrm{~g}$.

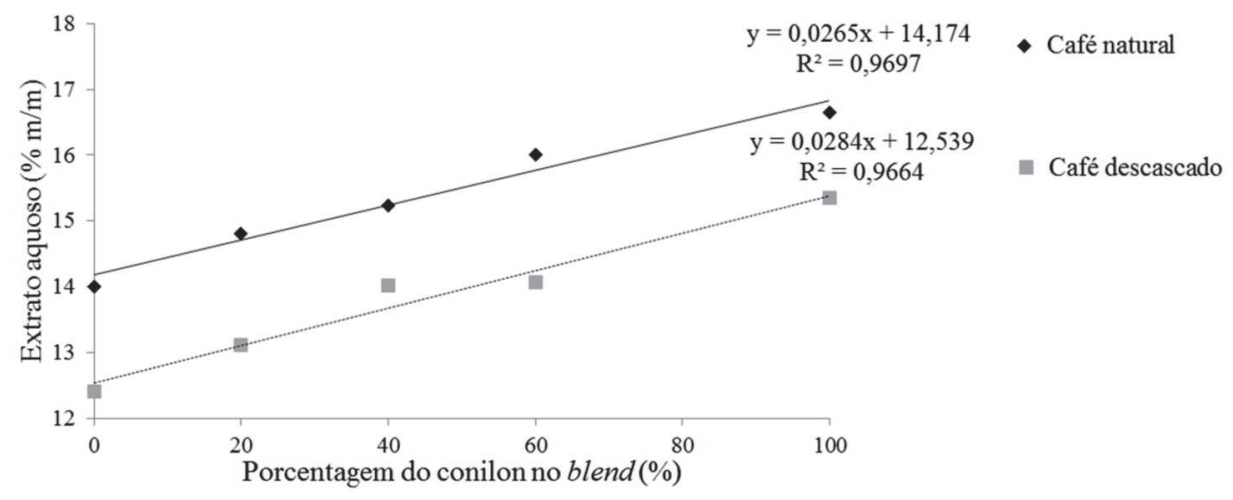

Figura 3: Valores de EA da bebida de café expresso em função da adição de níveis crescentes de conilon no blend com arábica. 
se que o blend contendo $60 \%$ de café conilon apresentou maior intensidade de gosto amargo; entretanto, tal característica não alterou a aceitação do blend, uma vez que o teste de aceitação realizado com consumidores demonstrou não haver diferenças na aceitação sensorial das bebidas de café expresso preparadas com os diferentes blends estudados, para as duas formas de processamento (natural e descascado).

Os resultados do presente estudo demonstram a viabilidade da utilização de café conilon em blends com arábica quando se desejam bebidas com maior teor de extrato aquoso (mais encorpadas), como nos setores de café solúvel e de café tipo expresso.

\section{CONCLUSÃO}

O processamento do café por via seca resulta em bebidas com maior teor de extrato aquoso.

Em bebidas de café expresso a utilização blends de café conilon com café arábica acarreta menor acidez, maior $\mathrm{pH}$ e maior teor de extrato aquoso, podendo-se recomendar o uso de café conilon natural em mistura com café arabica quando se deseja obter bebidas com maior teor de extrato aquoso.

\section{AGRADECIMENTOS}

Ao Instituto Capixaba de Pesquisa, Assistência Técnica e Extensão Rural (INCAPER), pelo processamento e doação das amostras de café, e à Universidade Federal do Espírito Santo, pela bolsa concedida.

\section{REFERÊNCIAS}

Albanese D, Di Matteo M, Poina M \& Spagnamusso S (2009) Espresso coffee (EC) by POD: Study of thermal profile during extraction process and influence of water temperature on chemical-physical and sensorial properties. Food Research International, 42:727-732.

Associação Brasileira da Indústria de Café - ABIC (2012) Norma de qualidade recomendável e boas práticas de fabricação de cafés torrados em grão e cafés torrados e moídos. Disponível em: <http:// www.abic.com.br/publique/media/Norma\%20de\%20qualidade.pdf $>$. Acessado em: 13 de novembro de 2012.

Brasil (1999) Agência Nacional de Vigilância Sanitária. Portaria n ${ }^{\circ} 377$, de 26 de abril de 1999. Aprova o regulamento técnico para fixação de identificação e qualidade de café torrado em grão e café torrado e moído. Disponível em: <http://www.anvisa.gov.br/legis/portarias/ 377_99.htm>. Acessado em: 21 de novembro de 2012.

Brasil (2003) Ministério da Agricultura, Pecuária e Abastecimento. Instrução normativa $n^{\circ} 8$, de 11 de junho de 2003. Aprova o regulamento técnico de identidade e de qualidade para a classificação do café beneficiado grão cru. Disponível em: <http://www.abic.com.br/publique/media/NMQ_LEGISLAcaO_IN8.pdf >. Acessado em: 21 de novembro de 2011

Brasil (2010) Ministério da Agricultura, Pecuária e Abastecimento. Instrução normativa $\mathrm{n}^{\circ} 16$, de 24 de maio de 2010. Aprova o regulamento técnico para o café torrado em grão e para o café torrado e moído. Disponível em: <http://www.sindicafesp.com.br/arquivos/ sindi_leg_regulamentotecnicoIN16.pdf >. Acessado em: 12 de novembro de 2012 .
Centro de Desenvolvimento Tecnológico do Café - CETCAF (2012) Estudo de qualidade dos diferentes tipos de café conilon produzidos no ES. Disponível em: <http://www.cetcaf.com.br/ $\mathrm{p}$ a d r a o \% 20 b e b i d a $\% \begin{array}{llllllllll}2 & 0 & \mathrm{c} & \mathrm{o} & \mathrm{n} & \mathrm{i} & 1 & \mathrm{o} & \mathrm{n} / \mathrm{l}\end{array}$ projeto\%20padraobebidaconilon.htm>. Acessado em: 12 de novembro de 2012.

Clifford MN \& Wight J (1979) Chlorogenic acids, their complex nature and routine determination in coffee beans. Food Chemistry, 4:63-71.

Companhia Nacional de Abastecimento - CONAB (2013) Safra de Café 2013: primeira estimativa. Disponível em: <http://www.conab.gov.br/ O 1 a 1 a C M S / u p 1 o a d s / a r q u i v o s / 13_01_09_17_43_49_boletim_cafe_janeiro_2013.pdf >. Acessado em: 18 de fevereiro de 2013.

Duarte GS, Pereira AA \& Farah A (2010) Chlorogenic acids and other relevant compounds in Brazilian coffees processed by semi-dry and wet post-harvesting methods. Food Chemistry, 118:851-855.

Fonseca AFA, Ferrão RG, Ferrão MAG, Verdin Filho AC \& Volpi OS (2007) Qualidade do café conilon: operações de colheita e pós-colheita. In: Ferrão RG, da Fonseca AFA, Bragança SM, Ferrão MAG \& De Muner LH (Eds.) Café Conilon. Vitória, Incaper. p. 501-520.

Instituto Adolfo Lutz (IAL) (2008) Métodos físico-químicos para análise de alimentos. $4^{\mathrm{a}}$ ed. São Paulo, Instituto Adolfo Lutz. 1020p. (Versão eletrônica).

Kleinwächter M \& Selmar D (2010) Influence of drying on the content of sugars in wet processed green Arabica coffees. Food Chemistry, 119:500-504.

Lima Filho T, Della Lucia SM, Saraiva SH, Carneiro JCS \& Roberto CD (2011) Perfil sensorial e aceitabilidade de bebidas de café tipo espresso preparadas a partir de blends de café arábica e conilon. Enciclopédia Biosfera, 7:01-17.

Lima Filho T, Della Lucia SM, Saraiva SH \& Sartori MA(2013) Composição físico-química e qualidade sensorial de café conilon produzido no Estado do Espírito Santo e submetido a diferentes formas de processamento. Semina: Ciências Agrárias, 34:1723-1730.

Mendes LC (2005) Estudos para determinação das melhores formulações de blends de café arábica ( $C$. arabica) com café robusta $(C$. canephora Conilon) para uso no setor de cafés torrados e moídos e de cafés espresso. Tese de Doutorado. Universidade Estadual de Campinas, Campinas. 186p.

Navarini L \& Rivetti D (2010) Water quality for Espresso coffee. Food Chemistry, 122:424-428.

Pimenta CJ (2003) Qualidade de café. $3^{\mathrm{a}}$ ed. Lavras, Editora UFLA. 304p.

Pinto NAVD, Fernandes SM, Giranda RN, Pereira RGFA \& Carvalho VD (2002) Avaliação de componentes químicos de padrões de bebida para preparo do café expresso. Ciência e Agrotecnologia, 26:826-829.

Ribeiro Júnior JI (2001) Análises estatísticas no SAEG. Viçosa, UFV. 301p.

Santos ESM (2010) Perfil sensorial e aceitabilidade do consumidor para blends de bebidas de café preparadas com grãos arábica (Coffea arabica L.) e conilon (Coffea canephora P.). Dissertação de Mestrado. Universidade Federal Rural do Rio de Janeiro, Seropédica. $83 \mathrm{p}$.

Santos MA, Chalfoun SM \& Pimenta CJ (2009) Influência do processamento por via úmida e tipos de secagem sobre a composição, físico química e química do café (Coffea arábica L). Ciência Agrotecnologia, 33:213-218.

Saraiva SHS, Zeferino LB, Della Lucia SM, Teixeira LJQ \& Junqueira MS (2010) Efeito do processamento pós-colheita sobre a qualidade do café conillon. Enciclopédia Biosfera, 6:01-09.

Siqueira HH \& Abreu CMP (2006) Composição físico-química e qualidade do café submetido a dois tipos de torração e com diferentes formas de processamento. Ciência e Agrotecnologia, 30:112-117. 